\title{
Glaciar Pirámide: Características y evolución reciente de un glaciar cubierto. Evidencias del cambio climático
}

\author{
Francisco Ferrando Acuña ${ }^{1}$, fferrand@uchilefau.cl
}

\begin{abstract}
RESUMEN
Se analiza la situación del Glaciar Pirámide, ubicado en la cuenca andina del Río Maipo, a los $33^{\circ}$ $35^{\prime}$ S y $69^{\circ}$ 53' W, y a una altitud media de $3565 \mathrm{msnm}$, desde un punto de vista tanto cuantitativo como cualitativo. Con una longitud de 6,5 km, un espesor medio de 54,64 m y una sección gélida de 0,026 km2, se calcula un volumen de hielo sucio equivalente en agua de 135,2 millones de litros. Morfológicamente corresponde a la tipología de glaciar cubierto, cuyo manto detrítico presenta espesores variables entre $30 \mathrm{~cm}$ y $1 \mathrm{~m}$, lo que relacionado con una gradiente media de $4,2^{\circ}$ determina un nivel de avance nulo. Ello se corrobora con la ausencia de burletes y surcos transversos propios de glaciares rocosos activos. En cambio, su superficie presenta una topografía caótica producto de ablación diferencial según en espesor del manto morrénico. En ella se presentan expresiones de termokarst, tales como moulins y depresiones de colapso con paredes de hielo de 20 a $30 \mathrm{~m}$ en las que se aprecian múltiples estratos detrítico-gélidos. En ellas se aprecian continuos derrumbes del material de cubierta, así como flujos de agua de fusión que circulan en la zona de contacto (capa activa). En el fondo de las depresiones se producen cuerpos lagunares de diferentes dimensiones así como quedan a la vista conductos intraglaciarios ocupados por flujos hídricos estacionales. Las dimensiones de estas formas de ablación y derrumbe han registrado variaciones en sus dimensiones, así como han aparecido nuevas depresiones y acentuado las irregularidades topográficas, lo cual revela un franco balance de masa negativo con incremento de los procesos de derretimiento, adelgazamiento y colapso de la masa de hielo, lo cual se asocia con la disminución de la alimentación por predomino del fenómeno La Niña desde el año 2009 y la tendencia al aumento de las temperaturas en la cuenca andina del Río Maipo.
\end{abstract}

Palabras clave: Glaciar cubierto, morfología, morfodinámica, derrumbes, ablación, calentamiento.

\section{Pirámide Glacier: Characteristics and evolution of a mantled glacier. Climatic change evidences}

\begin{abstract}
This research analyses,from a point of view both quantitative and qualitative, the situation of the Pyramid Glacier, located in the Andean basin of the Maipo River, at $33^{\circ} 35^{\prime} \mathrm{S}$ and $69^{\circ} 53^{\prime} \mathrm{W}$, with an average altitude of $3565 \mathrm{~m}$. With a length of $6.5 \mathrm{~km}$, an average thickness of $54,64 \mathrm{~m}$ and an icy section of $0,026 \mathrm{~km} 2$, is estimated a volume of dirty ice equivalent in 135,2 million liters of water. Morphologically corresponds to the type of covered glacier, whose debris mantle presents varying thickness between $30 \mathrm{~cm}$ and $1 \mathrm{~m}$, which related to an average of $4.2^{\circ}$ gradient determines none advance movement. This is corroborated by the absence of ridges and furrows that are properly of the active rock glaciers. On the other hand, its surface presents a chaotic topography product of differential ablation according to thickness of the morainic mantle. It presents thermokarst phenomena, like moulins, kettles and depressions of collapse with walls of ice 20 to 30 meters high, where there are multiple debris-icy layers. These walls presents continuous landslides of detritic material, as well as streams of melt water that circulate in the contact zone (active layer). At the bottom of depressions occur lagoons of different dimensions as well as tunnels occupied by seasonal water flows. The dimensions of these forms of ablation and collapse have registered variations in its dimensions, as well as have appear new depressions and accentuate the topographic irregularities, which reveals a strong negative
\end{abstract}

1 Departamento de Geografía, Universidad de Chile, Chile. Portugal 084, Santiago, R.M, Chile. 
mass balance with increase of the processes of melting, thinning and instability of the ice mass, which is associated with the decrease in the in-puts because dominance of the La Niña phenomenon since 2009 and the rising temperatures trends as shows the $0^{\circ} \mathrm{C}$ isotherm altitudinal changes.

Keywords: Mantled glacier, morphology, morpho-dynamic, slumps, ablation, warming.

Recibido el 20 de noviembre de 2012, aceptado el 10 de diciembre de 2012.

\section{INTRODUCCIÓN}

El calentamiento global, en tanto parte de los fenómenos asociados a las tendencias del cambio climático, está afectando con mayor o menor intensidad a diferentes componentes del sistema natural. En este sentido, ciertos elementos o subsistemas reaccionan de forma más rápida evidenciando su mayor sensibilidad a las modificaciones ambientales, sean estas naturales o inducidas por el hombre.

En este contexto, los glaciosistemas a nivel planetario están exhibiendo una degradación derivada de un balance de masa predominantemente negativo de los cuerpos de hielo. Como una forma particular de ellos y expresión singular del permafrost, los glaciares rocosos en general, y en particular un glaciar cubierto de los Andes occidentales de Chile central, el Glaciar Pirámide, ha estado registrando cambios notables en su estado y morfología superficial a pesar de la exposición indirecta del hielo al Cambio Climático Global (CCG), convirtiéndose en una suerte de indicador-revelador de las tendencias climáticas.

Como expresión de la presencia de permafrost en las latitudes templadas de la Cordillera de los Andes, se registra un importante número de glaciares rocosos correspondientes a prácticamente toda la tipología de formas y estados evolutivos (FERRANDO, 2003). Entre ellos, el Glaciar Pirámide corresponde a un glaciar cubierto, el cual está experimentando importantes y rápidos cambios en su estado interno y aspecto superficial, lo cual revela alteraciones en la relación alimentaciónconsunción, las que proyectadas a todos los glaciares rocosos de la cuenca del Río Maipo (MARANGUNIC, 1979) en el tiempo hablan de una trascendente disminución de las reservas hídricas que alimentan el principal sistema hidrológico de la región Metropolitana de Santiago de Chile.

En las siguientes líneas se dan a conocer aquellos aspectos de revelan un claro balance negativo en la masa de hielo de este glaciar durante la última década, entre las que se cuentan colapsos internos y formas de termokarst.

\section{Área de estudio}

El área de estudio corresponde a la cuenca superior del Río Yeso, afluente andino del Río Maipo, sistema hidrológico principal de la Región Metropolitana de Santiago de Chile. En dicho sector, una de las subcuencas alimentadores presenta un glaciar cubierto denominado Glaciar Pirámide, el cual es el objeto de esta investigación. Ubicado en un valle de exposición sur al lado occidental de la divisoria continental, se extiende entre

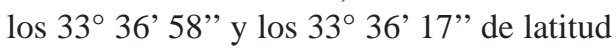
S, y a una longitud W media de 6953' 46”, W. (Fig. 1) 


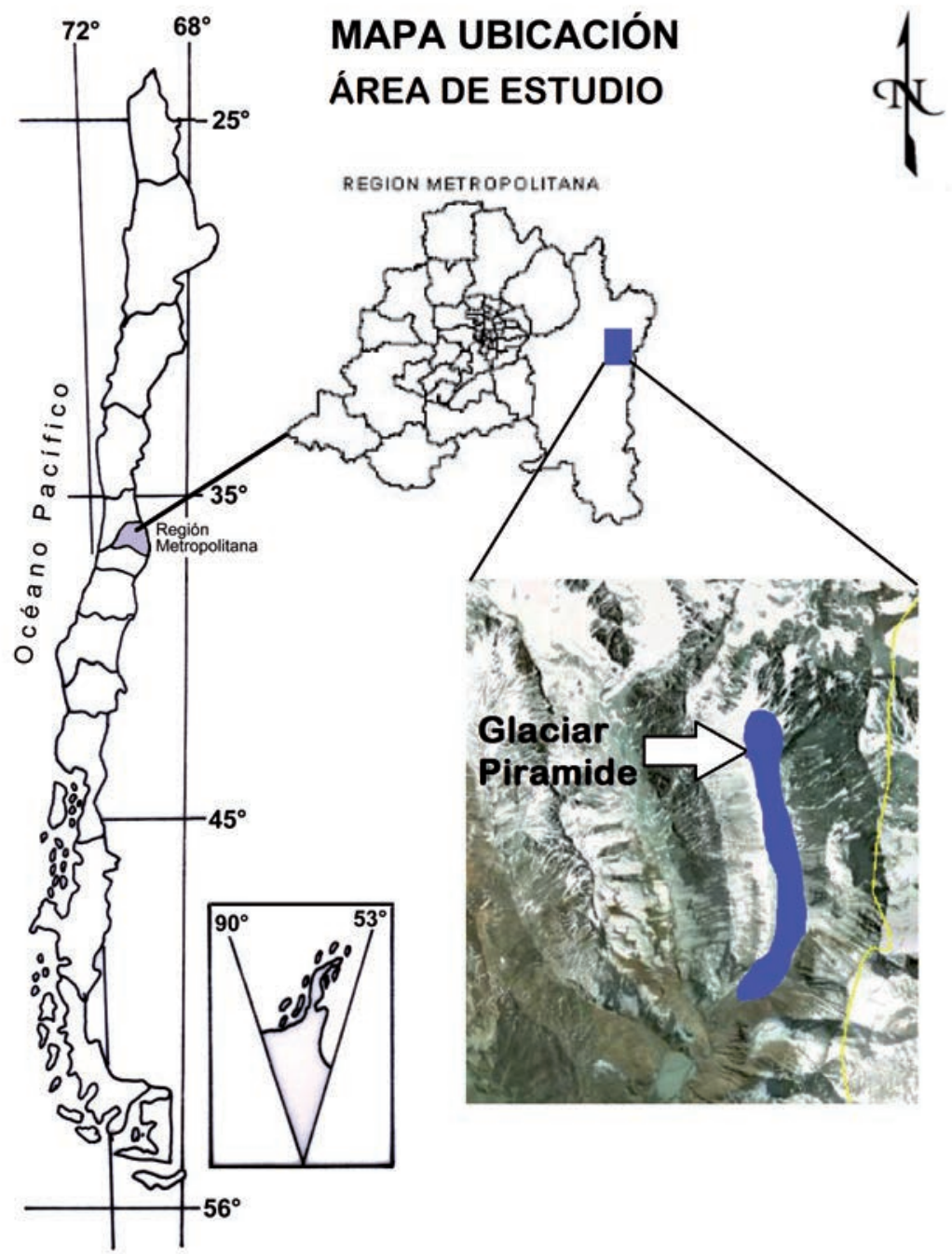

Fig. 1: Localización área de estudio.

Fig. 1. Location of the study area.

\section{MATERIALES Y MÉTODOS}

Los materiales utilizados corresponden básicamente a cartas topográficas escala 1:50.000 e imágenes satelitales más instrumentos básicos de campo como altímetro, clinómetro y huincha métrica. Metodológicamente, se trabajó en base a interpretaciones de imágenes y actividades de campo en diferentes periodos, las que han permitido medir, observar directamente y registrar los cambios que está experimentando este glaciar cubierto por comparación entre iguales sitios de su superficie. El material gráfico colectado en terreno ha sido fundamental para los posteriores análisis evolutivos y las interpretaciones llevadas a cabo en gabinete. 
Paralelamente, en base a las mediciones realizadas y cálculos posteriores, se procede a generar información sobre el volumen de hielos existente y su equivalente en agua. Ello se realiza mediante mediciones tanto directas como sobre cartas topográficas en las que se ha vaciado la información extraída de las imágenes satelitales, específicamente para determinación del largo y ancho medio.

Luego se lleva a cabo una aplicación comparativa de las relaciones cuantitativas desarrolladas por CHEN \& OHMURA (1990), MEIER \& BAHR (1996), BRENNING (2005) y MARANGUNIC (2010), las que permiten calcular tanto el espesor medio como el volumen de hielo. Estos resultados son comparados con los arrojados por el cálculo de la "sección gélida" de la lengua del glaciar cubierto basada en el desarrollo gráfico a escala de la parábola que describe la sección transversal del valle glacial, considerando la proyección subglacial de la gradiente predominante de las laderas, la cual en este caso tiene un valor promedio de $30^{\circ}$, excluyendo el sector del circo. Esta sección gélida, equivalente a la sección mojada en el caso de aforos fluviales, posibilita calcular el volumen de hielo al multiplicarla por el largo del cuerpo de hielo cubierto. Los datos para este proceso fueron obtenidos tanto en forma directa (mediciones en terreno con eclímetro y taquímetro) como indirecta a partir de imágenes rectificadas y cartas topográficas 1:50.000.

Para la conversión en agua equivalente se utiliza 0.8 como factor de acuerdo a lo señalado por Marangunic (2010), lo cual es coincidente con las observaciones realizadas en terreno (Fig. 2).

\section{RESULTADOS Y DISCUSIÓN}

\section{Características glaciométricas y volumétricas}

El Glaciar Pirámide se encuentra localizado en las nacientes del Río Yeso, uno de los principales afluentes del Río Maipo. Tiene por coordenadas centrales $33^{\circ} 35^{\prime} \mathrm{S}$ de latitud Sur y 69 53' de longitud Oeste. Su altitud varia entre3870 msnm en su cabecera (base del circo glacial) y 3259 msnm en su parte frontal, la cual presenta un potente depósito morrénico. Su eje longitudinal tiene una dirección NNW-SSE en sus dos tercios superiores, para luego describir una curva hacia el SW en su tercio inferior. El circo glacial se ubica en su extremo $\mathrm{N}$ con altitudes de la línea de cresta que supera en varios puntos los $5000 \mathrm{msnm}$, lo que genera una pared rocosa de $\pm 60^{\circ}$ de pendiente y poco más de $1000 \mathrm{~m}$ de desnivel máximo. (Fig. 3). 


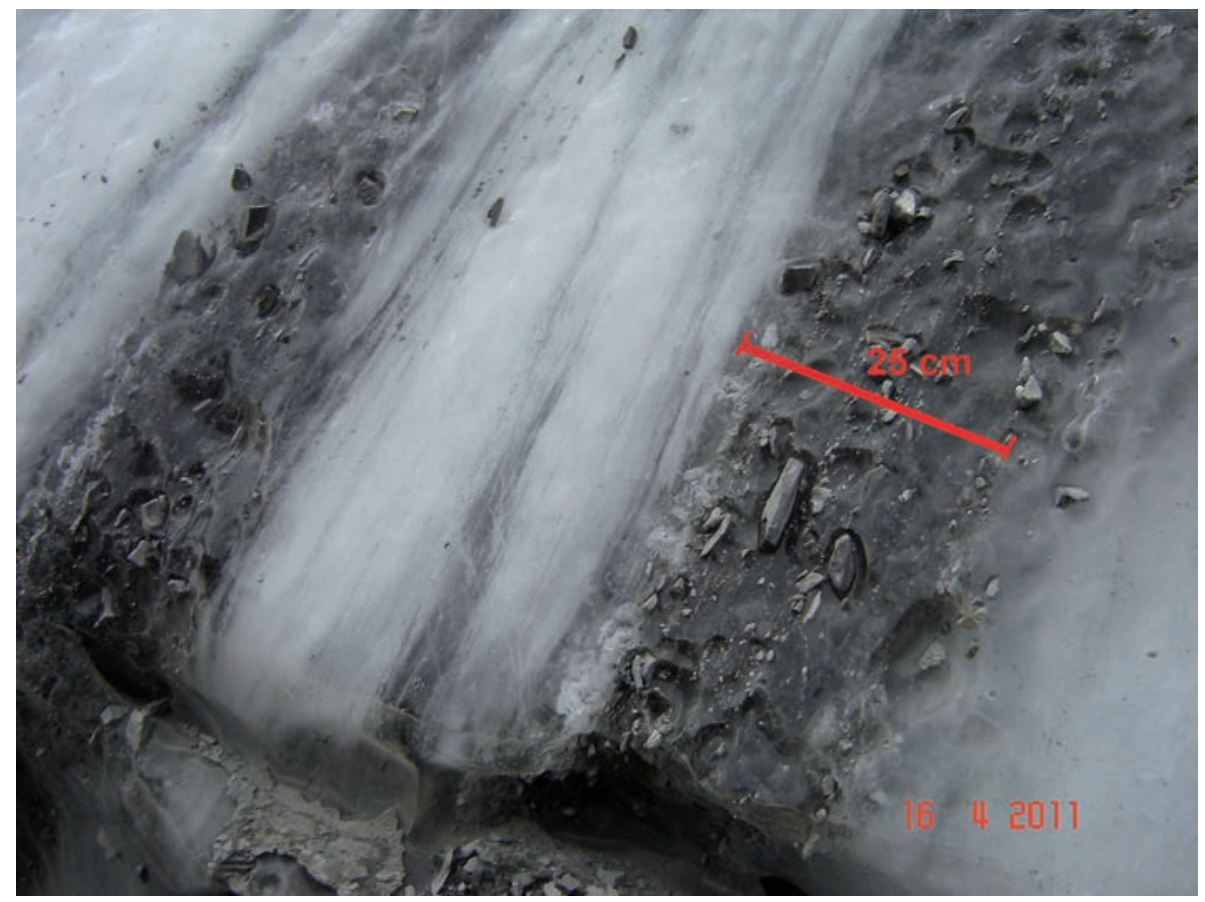

Fig. 2. Detalle de estratos glacio-detríticos dentro de la masa del glaciar. Espesor $=20-30 \mathrm{~cm}$.

Fig. 2. Detail of glacio-detrital stratus in the glacier. Thickness $=20-30 \mathrm{~cm}$.

Dada su orientación general, se trata de una lengua de hielo en exposición de umbría, con un eje longitudinal que se extiende por $6,5 \mathrm{~km}$ y un ancho medio de $470 \mathrm{~m}$. De acuerdo a ello, la superficie del glaciar asciende a $3,055 \mathrm{~km}^{2}$.

Determinada su superficie, se requiere conocer el espesor medio para poder estimar su volumen. Con este objeto, para el cálculo del espesor, se utiliza en primer lugar la relación establecida por CHEN \& OMURA (1990) la cual establece que:

Espesor $(\mathrm{m})=28,5\left(\text { Área en } \mathrm{km}^{2}\right)^{0,357}$

De acuerdo a esta expresión, el espesor medio del Glaciar Pirámide sería de: 42,46 m. Basándose en esta cifra, la sección gélida correspondería a 19.956,2 m², y el volumen del glaciar alcanzaría 129,7 millones de $\mathrm{m}^{3}$ de hielo sucio $\left(0,1297 \mathrm{~km}^{3}\right)$. 


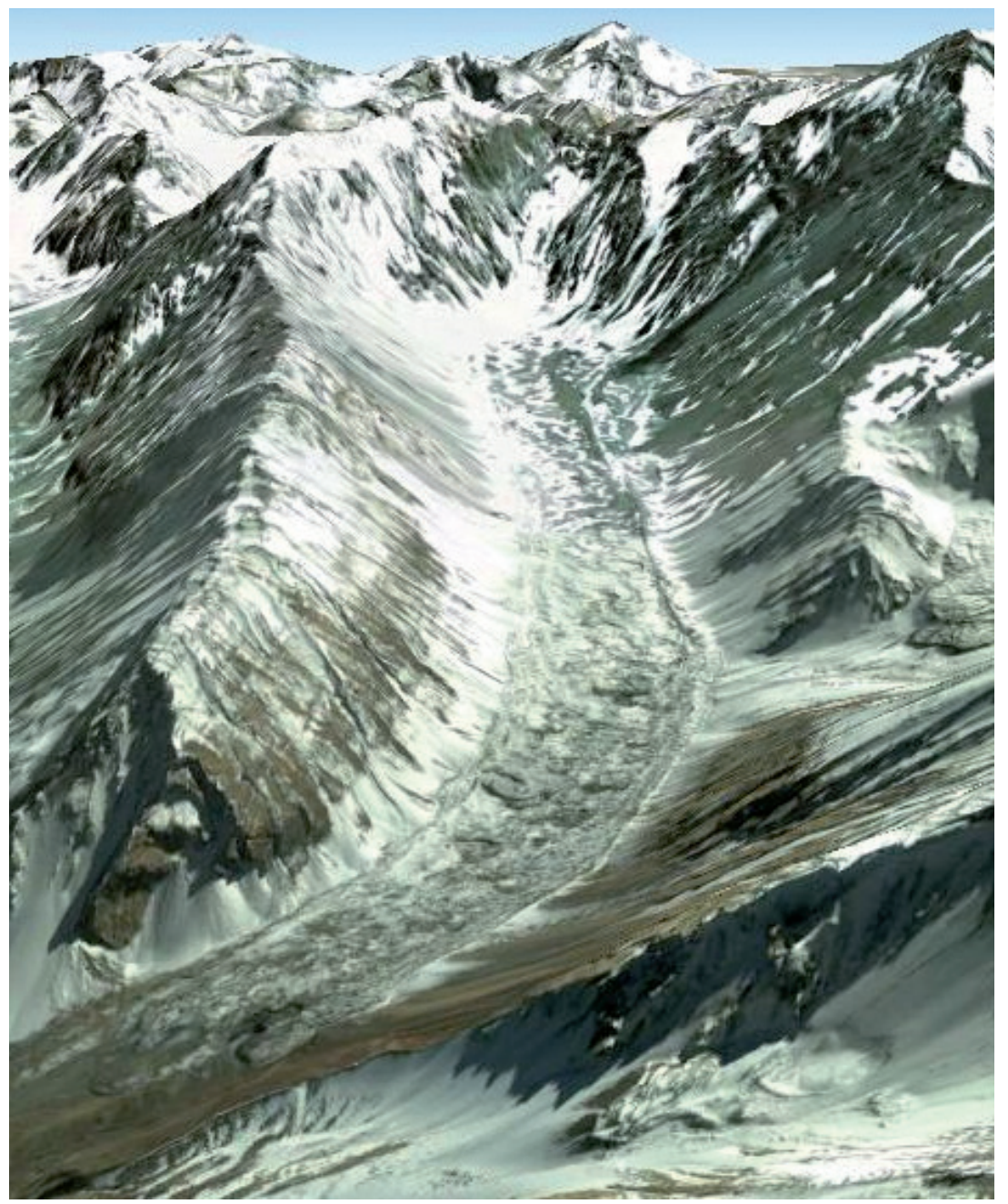

Fig. 3. Vista hacia el $\mathbf{N}$ del Glaciar Pirámide, de tipo cubierto. Valle con laderas regladas periglaciales.

Fig. 3. View $\mathbf{N}$ of the mantled Pirámide Glacier. Valley with periglacial rectilinear slopes.

Utilizando la relación establecida por MEIER \& BAHR (1996), la cual establece que:

$$
\mathrm{V}=0,048(\mathrm{~A})^{1,36}
$$

Donde: V es el volumen y A el área del glaciar.

Se obtiene $V=0,048(3,055)^{1,36}$, es decir, $0,219 \mathrm{~km}^{3}$.Este resultado en relación con el área conduce a establecer que el espesor medio sería de $71,68 \mathrm{~m}$. Si se emplea la relación establecida por BRENNING (2005) para el cálculo del espesor medio, es decir:

$$
\mathrm{E}_{(\mathrm{m})}=50\left(\text { Área }_{\mathrm{km} 2}\right)^{0,2}
$$

Se obtiene un E igual a: 62,51 m. Este espesor, el cual es cerca de un 30\% superior al basado en CHEN \& OHMURA (1990), al ser multiplicado por el área del glaciar arroja un volumen de $0,191 \mathrm{~km}^{3}$. 
Respecto de la relación establecida por MARANGUNIC (2010) para el cálculo del espesor de un glaciar, si bien su empleo está restringido a glaciares menores de $1 \mathrm{~km}^{2}$, aquí se la utiliza con fines comparativos. Dicha relación expresa que el espesor medio de hielo es igual a:

$$
\mathrm{E}_{(\mathrm{km})}=0,00944\left(\text { Área }_{\mathrm{km} 2}\right)^{0,65185}
$$

De acuerdo con ella, el espesor del Glaciar Pirámide alcanzaría unos 19,47 m, lo cual se encuentra claramente por debajo de las cifras anteriores y de lo observado empíricamente. De hecho, en algunos sectores donde se evidencian colapsos internos del glaciar, los espesores expuestos superan fácilmente los $20 \mathrm{~m}$ sin significar ello que se trate del espesor total. La formación de un cuerpo lagunar en la depresión generada es un indicador de la presencia de un sustrato impermeable, lo cual indica efectivamente la presencia de hielo ocupando el subsuelo así como el espacio poroso intramorrénico del sustrato. (Fig. 4).

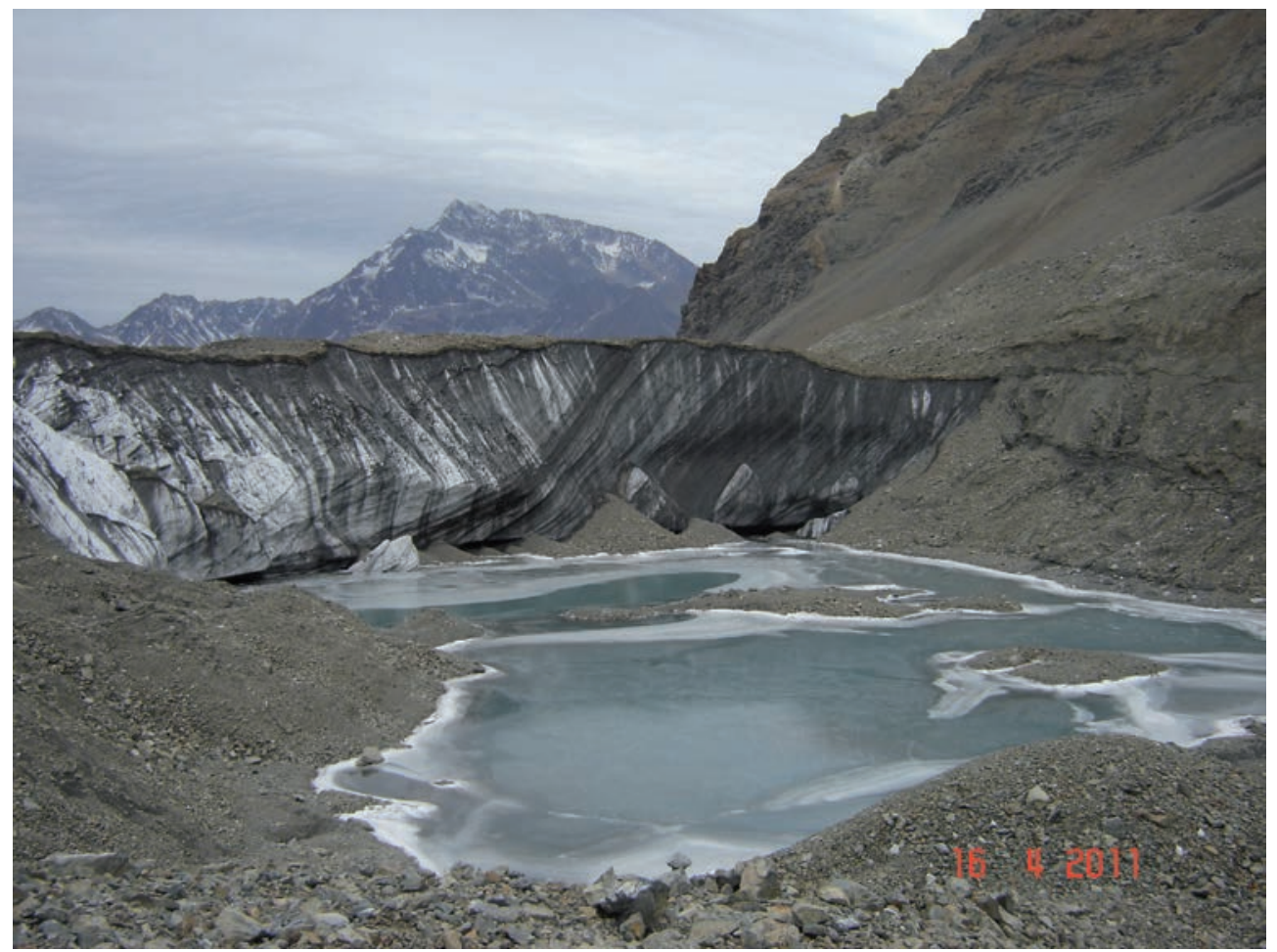

Fig. 4. Colapso interno del glaciar cubierto deja expuesto un gran espesor de hielo detrítico estratificado. El agua de fusión arrastra sedimentos sobre el escarpe de hielo.

Fig. 4. Internal collapse of the mantled glacier leaves exposed as great thickness of stratified detritic ice. The melting water transport sediments over the ice cliff.

Como una forma de revisar estos resultados, se considera el ancho medio del glaciar junto con la forma cóncava típica del fondo de un auge, cuya sección transversal tiene gran semejanza con el desarrollo de una parábola. En el caso de una parábola se cumple que el trazo recto $\mathrm{R}$ (equivalente al ancho del glaciar en superficie) al ser 
dividido por 4 representa la distancia entre el foco y el vértice de esta $\left(\mathrm{D}_{\mathrm{FV}}\right)$, lo que sería equivalente al espesor máximo de un glaciar. Tomando en cuenta que los flancos del valle del Glaciar Pirámide en su tercio inferior presentan un gradiente media de $30^{\circ}$, y proyectando el desarrollo más probable de la curva bajo el hielo conforme al valle gemelo adyacente, se obtiene una proporción ancho/espesor de 5,2/1, de lo que resulta un espesor máximo de 89,85 m. (Fig. 5).

De acuerdo a ello y al desarrollo de la parábola teórica para la gradiente indicada, se establece que el espesor medio del glaciar responde a la siguiente relación:

$$
\text { Espesor medio }(\mathrm{m})=0,608\left(\mathrm{D}_{\mathrm{FV}}\right)
$$

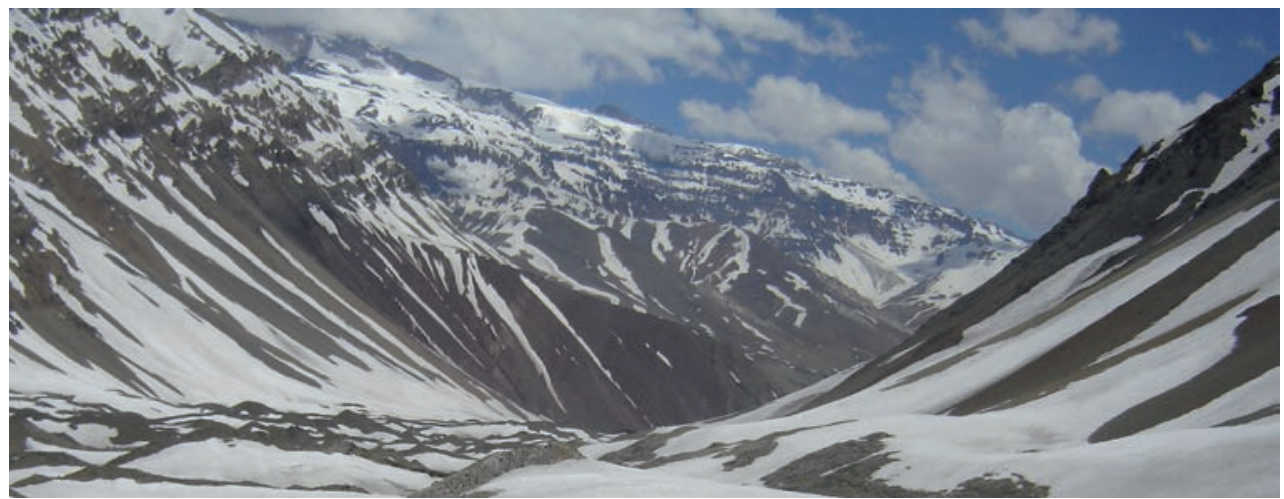

Fig. 5. Sección transversal del valle glacial, de configuración abierta.

Fig. 5. View of the wide transverse section of the glacial valley.

Esta relación se ve corroborada por la relación entre la sección gélida establecida por planimetría para el glaciar en base al dibujo a escala representativo de la morfología de la sección transversal del valle $\left(25.679,38 \mathrm{~m}^{2}\right)$ y su ancho. En la figura 6 se aprecia la sección transversal representativa establecida para el valle del Glaciar Pirámide, la que se ve reforzada por el perfil transversal del valle gemelo ubicado inmediato al W y que carece de un cuerpo glaciario.

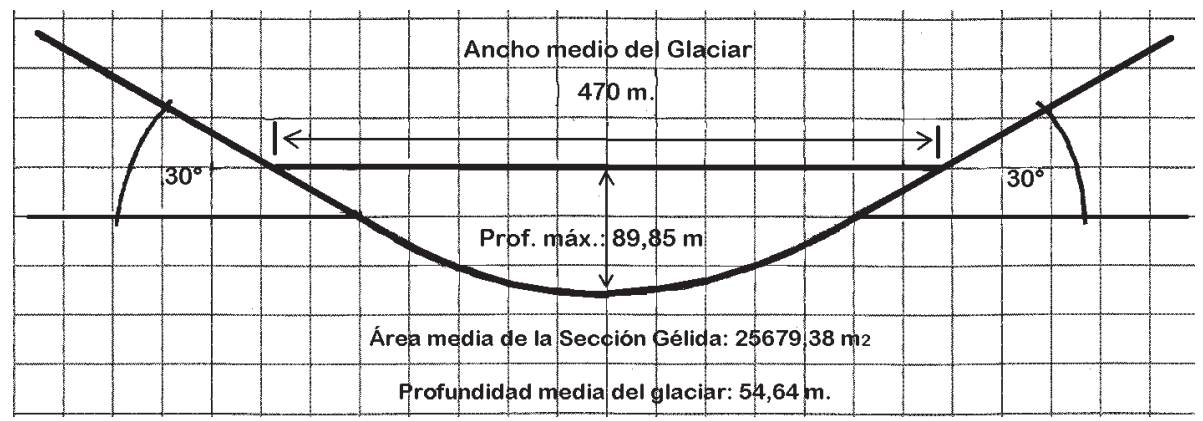

Fig. 6. Sección transversal representativa del valle del Glaciar Pirámide, usada para medir su espesor medio.

Fig. 6. Representative transverse section of the valley used for determine the Piramide Glacier mean thickness. 
De acuerdo a esta expresión y considerando el ancho medio del glaciar, el espesor medio alcanzaría los 54,64 m, lo cual representa un $28,7 \%$ mayor que el resultado que arroja la expresión de CHEN \& OMURA (1990), un $12,6 \%$ menor que la establecida en base a BRENNING (2005) y un $23,8 \%$ menor a la calculada según la formula de MEIER \& BAHR (1996). (Tabla n 1)

Tabla 1. Espesor medio del Glaciar Pirámide.

Table 1. Mean thickness of the Pirámide GLACIER.

\begin{tabular}{|ccc|}
\hline Autor & Año & $\begin{array}{c}\text { Espesor medio } \\
(\mathbf{m})\end{array}$ \\
\hline Chen \& Ohmura & 1990 & 42,46 \\
\hline Meier \& Bahr & 1996 & 71,68 \\
\hline Brenning & 2005 & 62,51 \\
\hline Ferrando & 2012 & 54,64 \\
\hline
\end{tabular}

Estas cifras están dentro de los valores establecidos como más frecuentes por MARANGUNIC (2010) para los Andes de Chile central, quien incluso señala que se han registrado espesores bastante superiores, llegando a alcanzar hasta $130 \mathrm{~m}$.

El espesor medio calculado en este estudio permite establecer una sección gélida que equivale aproximadamente a 0,026 $\mathrm{km}^{2}$. El producto de la sección gélida por el largo del glaciar (lo que es equivalente a la profundidad media multiplicada por la superficie) arroja como resultado la existencia aproximada de $0,169 \mathrm{~km}^{3}$ de hielo sucio. Este volumen expresado en agua a razón de 0,80 (tanto por la proporción hielo-agua como por el contenido detrítico interno) permite considerar un volumen equivalente a 135,2 millones de litros de agua (135.200 $\left.\mathrm{m}^{3}\right)$.

\section{Gradiente general}

Dado su largo y la diferencia altimétrica entre su origen y su frente $(611 \mathrm{~m})$, la pendiente media de este glaciar cubierto es de poco más de $4,2^{\circ}(9,4 \%)$, lo que representa una fuerza cinética potencial tan baja que, considerando un espesor medio de cubierta detrítica inferior a $1 \mathrm{~m}$, el movimiento de avance por esta causa es prácticamente nulo. Ello se confirma por el hecho que en el abultado depósito morrénico frontal no se registra signo alguno de avance, como bloques volcados, derrumbes o deformaciones recientes, hecho que se corresponde con las evidencias de descompresión longitudinal de la lengua cubierta por consunción, como se explica más adelante. Esta situación es acorde con las determinaciones de MARANGUNIC (2010) para glaciares rocosos de $50 \mathrm{~m}$ de espesor (Fig. 7). 


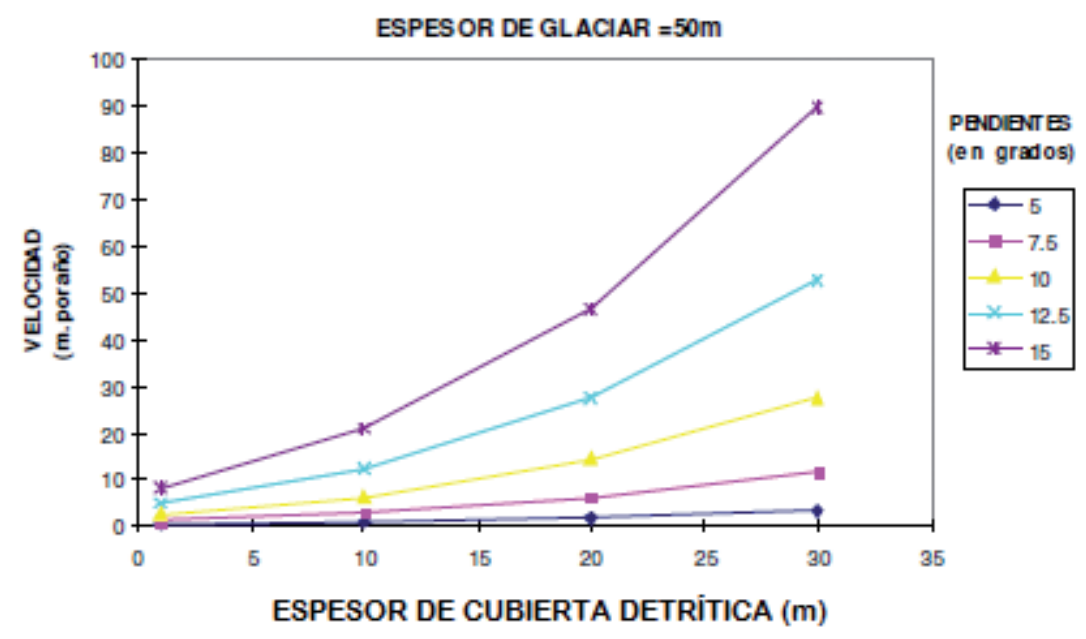

Fig. 7. Velocidad de un glaciar cubierto de $50 \mathrm{~m}$ de espesor vs. gradiente del perfil longitudinal y potencia de la cubierta detrítica. (MARANGUNIC 2010).

Fig. 7. Velocity of a mantled glacier (total thickness $=50 \mathrm{~m}$ ) vs. its longitudinal profile gradient and detritical mantle deep (MARANGUNIC, 2010).

\section{Características morfo-evolutivas y térmicas}

Glacio-dinámicamente, este cuerpo de hielo reúne todas las características de un glaciar de valle remanente, que por reducción paulatina de la alimentación, por efecto de la ablación superficial y de los flujos hídricos internos, comenzó a gradar hacia un glaciar cubierto, tanto producto de la acumulación superficial de detritos aportados desde los flancos del valle (de génesis periglacial), como de aquellos que van quedando expuestos por el efecto de la fusión superficial. De este modo se inicia la construcción de una suerte de pavimento detrítico que va creciendo en grado de cobertura como en espesor. Este fenómeno, propio de situaciones de balance de masa negativo, va creando un manto de sedimentos que en la medida que se engrosa va provocando un incremento en el aislamiento térmico de la masa de hielo subyacente respecto de la influencia atmosférica.
Conociendo las características internas del hielo que forma esta lengua cubierta, el cual exhibe múltiples bandas de sedimentos $\mathrm{y}$ detritos interestratificados (Fig. 2), es claro sustentar que una parte fundamental de los materiales de cubierta provienen de la morrena interna (material detrítico intraglacial).

A este respecto existen diferentes opiniones sobre la relación entre espesor y aislamiento térmico. Al respecto, mediciones de temperaturas realizadas en glaciares rocosos de la cuenca superior del Río Elqui revelan que dentro de la cubierta detrítica se registran aumentos de temperatura desde la superficie hasta alrededor de 0,5 a $1 \mathrm{~m}$ de profundidad y que luego esta comienza a decrecer con desigual velocidad hasta acercarse a los $0^{\circ} \mathrm{C}$ alrededor de $\operatorname{los} 3 \mathrm{~m}$ bajo la superficie. Ello se evidencia en las curvas-trompeta construidas con los datos de los sensores térmicos instalados en el glaciar cubierto de El Tapado a $4440 \mathrm{msnm}$, y de Llano de las Liebres a 4050 msnm (Fig. 8 y 9 respectivamente) (BRENNING et al. 2010). 

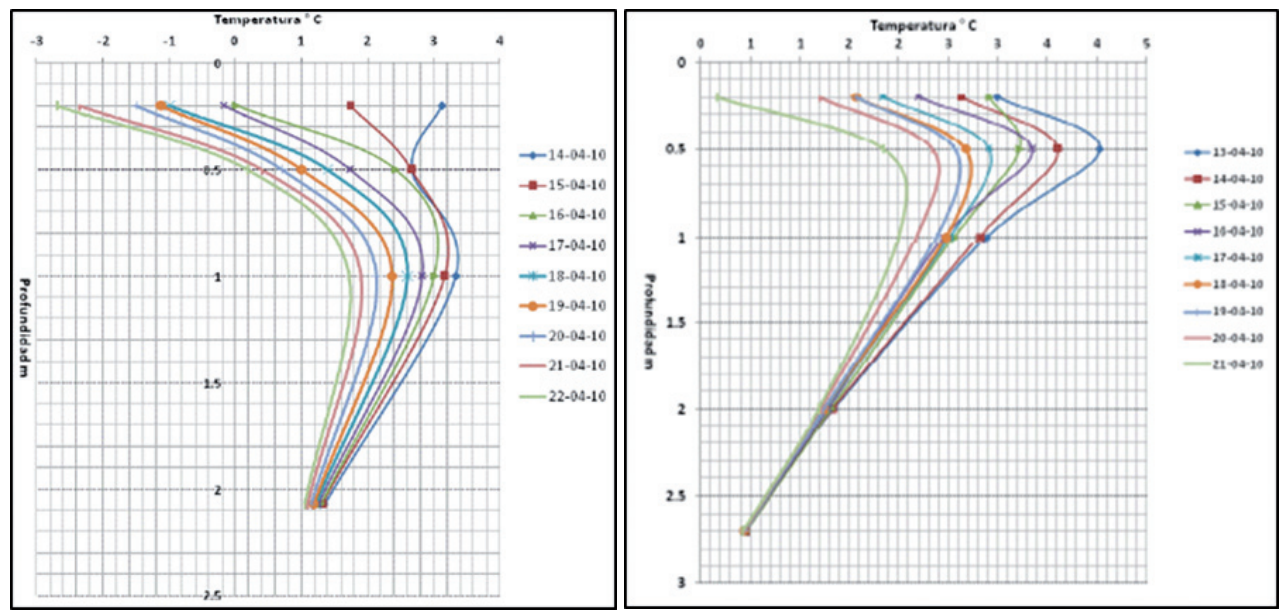

Fig. 8 y 9. Temperaturas dentro de la cubierta detrítica de los glaciares El Tapado (Izquierda) y Llano de las Liebres (Derecha) entre el 14 y el 22 de Abril de 2010 (BRENNING et al. 2010).

Figs. 8 and 9. Temperatures of the detrital mantle in the glaciers El Tapado (left) and Llano de las Liebres (right), April 14 - 22, 2010 (BRENNING et al. 2010).

En cuanto a lo observado en el Glaciar Pirámide, es posible observar en forma directa que con espesores variables entre 20 y $30 \mathrm{~cm}$ existe una suficiente trasmisión de calor como para provocar la presencia de escurrimientos líquidos en la superficie de contacto durante buena parte del día, lo que viene a configurar la clásica capa activa propia de este tipo de permafrost. (Fig. 10).

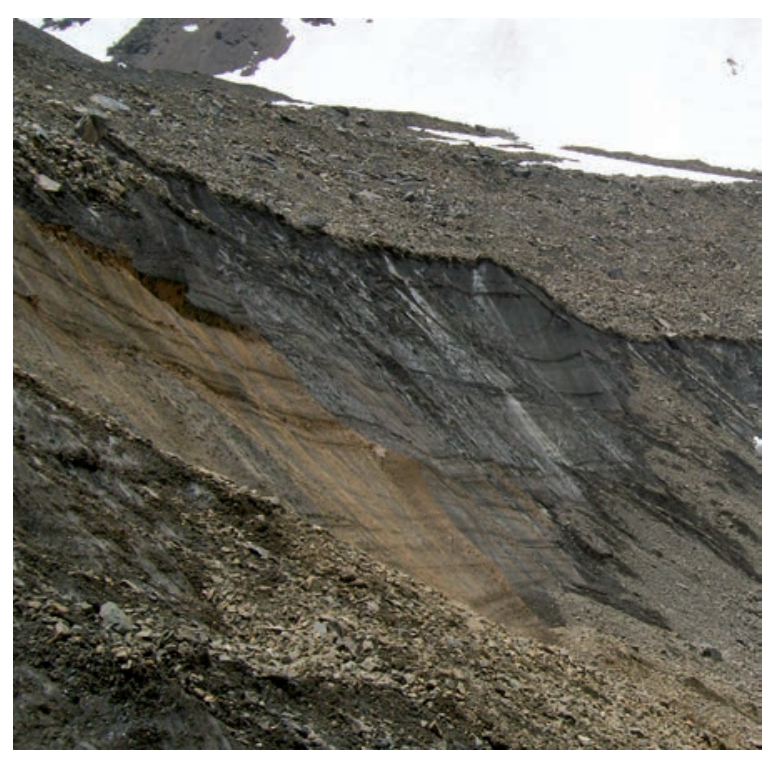

Fig. 10. Frentes de hielo expuestos del glaciar cubierto. La circulación hídrica (capa activa) genera desprendimientos desde el manto morrénico, cargados de fracciones finas y óxidos.

Fig. 10. Ice fronts of the mantled glacier. The hydric circulation into the active layer produces detrital flows from the morainic mantle, including fine sediments and oxides. 
Un aspecto relevante a considerar por su influencia en el proceso es la alta conductividad térmica de los materiales detríticos que conforman la cubierta, ya que tienen una naturaleza litológica predominantemente máfica, con predominio de rocas volcánicas de tipo andesítico y andesito-basáltico, junto con brechas volcánicas y areniscas de color gris.

Por otro lado, se evidencia una importante presencia de flujos hídricos por grietas y conductos interiores de la masa de hielo, los cuales quedan al descubierto por la ocurrencia de desplomes que revelan tanto las características del hielo y su estructura interna como los fenómenos de piping o vaciamiento por acción progresiva de los flujos hídricos intraglaciarios (Fig. 11). Lo señalado obedece a condiciones climáticas, principalmente los rangos térmicos, que desde el punto de vista térmico revelan ambientes de glaciares templados.

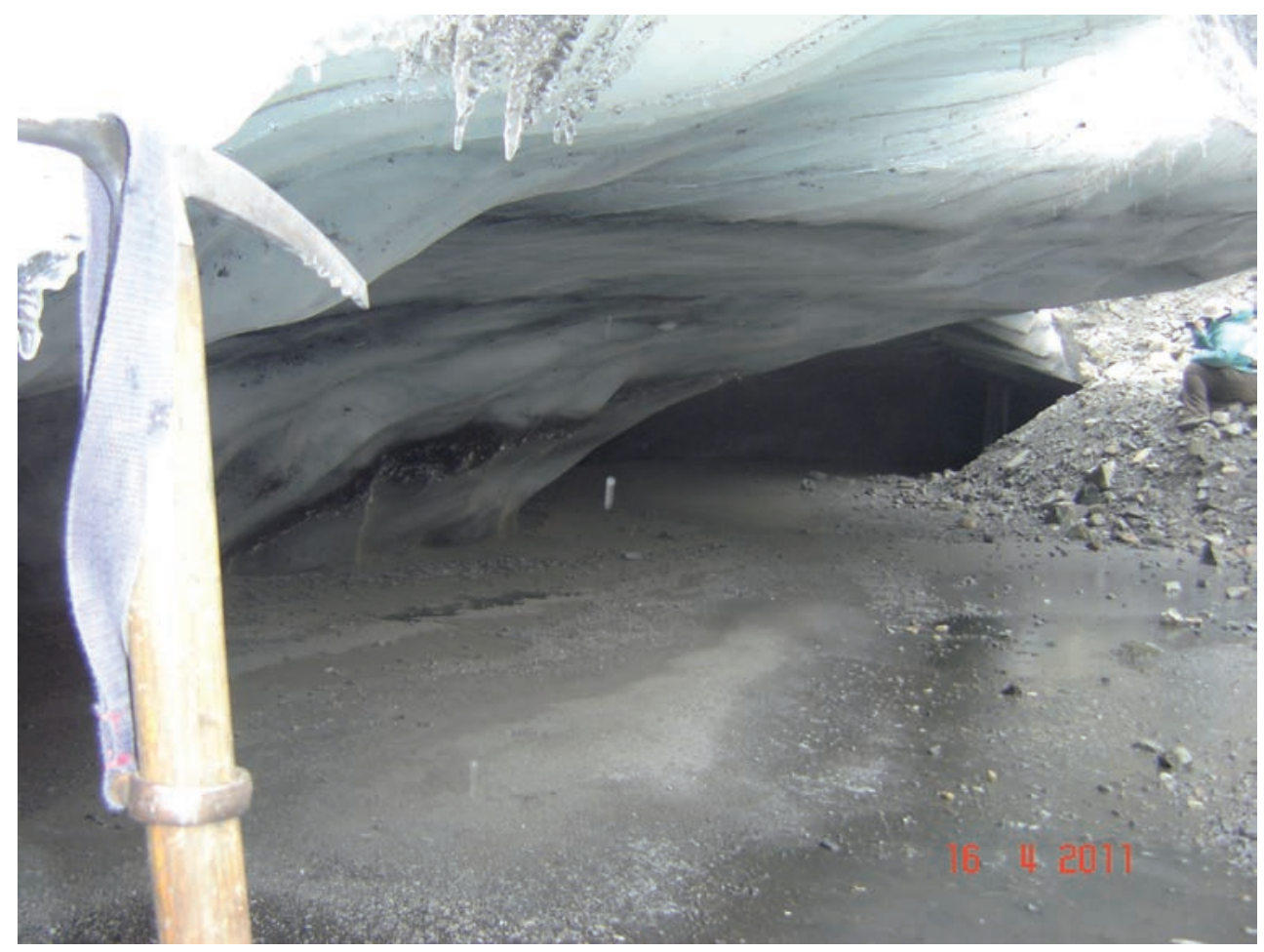

Fig. 11. Oquedad y conducto dentro del glaciar. La superficie del agua está congelada.

Fig. 11. Cavity and duct inside of the glacier. The surface of the water is frozen.

Otras consecuencias dicen relación con lo caótico de la morfología que presenta la superficie del glaciar cubierto (Fig. 12), observándose la ocurrencia de fenómenos de Termokarst de muy variadas dimensiones e intensidad, y presencia de quiebres y desnivelaciones de bloques de hielo, con modificación de la mecánica de ocurrencia (paso de fenómenos de glaciotectónica generados por compresión o empujes, a generados por fenómenos de distención, lo cual se observa en el cambio de orientación de los escarpes resultantes (por compresión los escarpes miran hacia valle abajo, a diferencia de los generados por distención cuya orientación es hacia valle arriba o al centro del hundimiento). 
En las subsidencias (colapsos internos por vaciamiento sub e intraglacial) se detectan cambios de las dimensiones (incremento de tamaño). Ello conlleva el aparecimiento de cuerpos lagunares y descubrimiento de segmentos de ductos intraglaciarios con cuerpos de agua congelados en superficie. en la carencia de burletes transversos y curvados según la eficiencia del empuje glacigénico, lo cual revela una baja en la alimentación al grado que es absolutamente insuficiente durante largo tiempo, lo que ha mantenido la masa del glaciar estática en términos de avance.

La inactividad del glaciar en términos de avance queda claramente expresada también

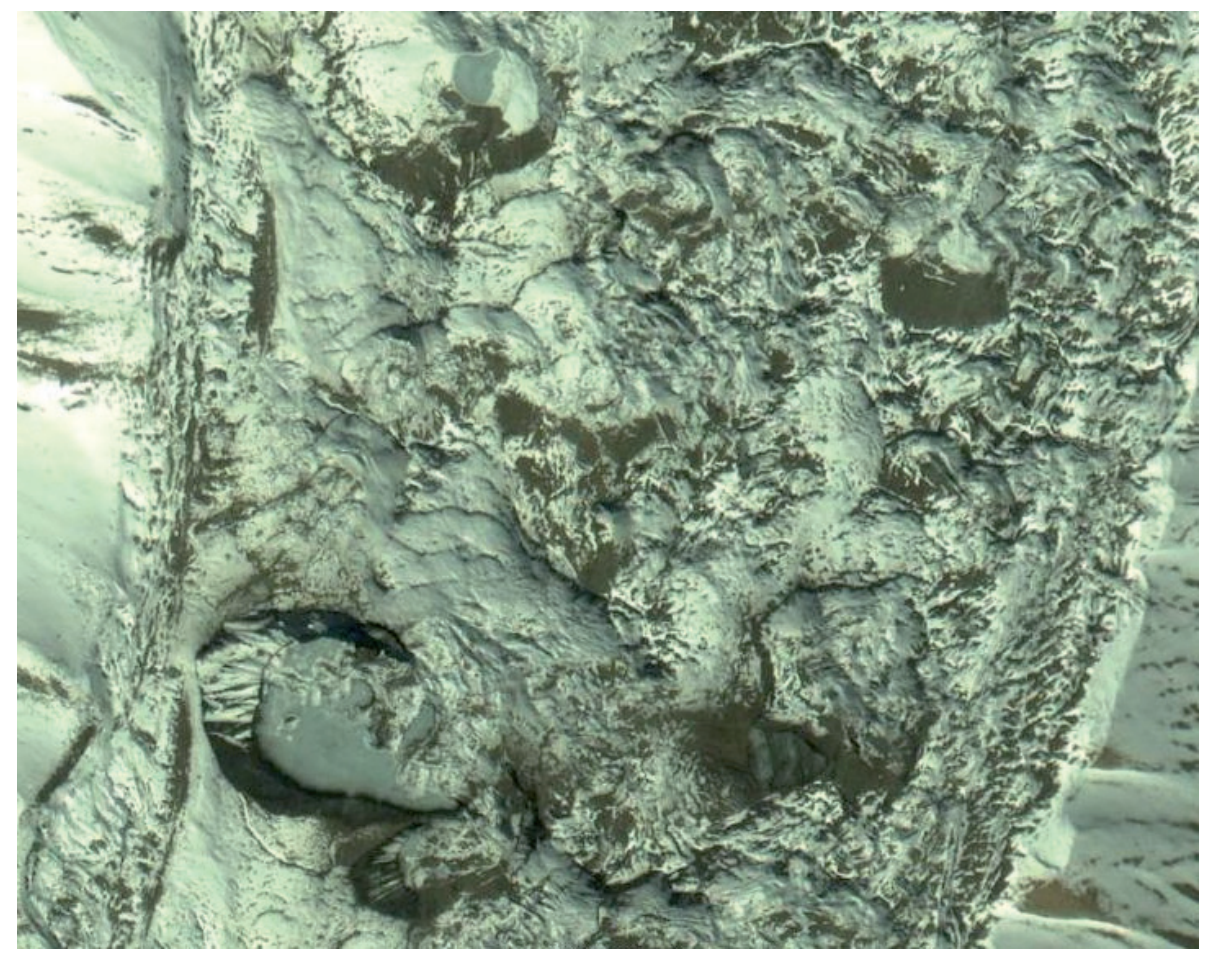

Fig. 12. Superficie caótica del Glaciar Pirámide con termokarst y sin evidencia de empuje glacial.

Fig. 12. Chaotic surface of the Piramide Glacier with thermokarst and without evidence of glacial push.

\section{Los depósitos morrénicos}

Además de la cubierta morrénica del glaciar, este presenta un sistema de morrenas laterales y una morrena frontal. En el extremo terminal, el depósito morrénico frontal tiene una extensión de $750 \mathrm{~m}$ en sentido NE-SW. Estos describen una forma de arco fuertemente masivo en su sector central. Los costados se van adelgazando hacia arriba y establecen una solución de continuidad con las morrenas laterales, las que se prolongan por los costados del glaciar hasta cerca de su naciente.

Estos cordones morrénicos laterales en algunas secciones longitudinales han actuado como elementos de contención de los aportes provenientes de las laderas, generando sectores de depresiones 
longitudinales en el tramo de contacto. En otros tramos con mayor aporte transversal han ocurrido rebalses, pasando los detritos de los flacos del valle a tomar contacto directo con el glaciar cubierto.

Entre el actual nivel de la masa de hielo cubierto y la altura de las morrenas laterales mejor conservadas se registra un desnivel del orden de 25 a $30 \mathrm{~m}$, lo cual indica un adelgazamiento considerable supuestamente a partir del inicio del período postglacial, hace unos 14.000 años BP según cronologías de las morrenas del sur de Chile (FERRANDO, 2002).

Por su parte, el depósito morrénico frontal se presenta dividido en dos conjuntos de forma caótica separados por una llanura sedimentaria de origen fluvioglacial de unos $300 \mathrm{~m}$ de largo por $100 \mathrm{~m}$ de ancho. De acuerdo a ello, este depósito plantea la ocurrencia de al menos dos estadios de avance dentro del proceso de retroceso general de los frentes de hielo desde inicios del Holoceno.

A este plano sedimentario fluvioglacial inter-morrénico acceden una serie de pequeñas quebradas por las que afluyen las aguas de fusión tanto glacial como nival según la estación del año. A partir de este depósito y producto de la concentración de las aguas de fusión de presenta una garganta epigénica de hidrodinámica torrencial que atraviesa el frente morrénico exterior con un fuerte grado de encajamiento (Fig. 13).

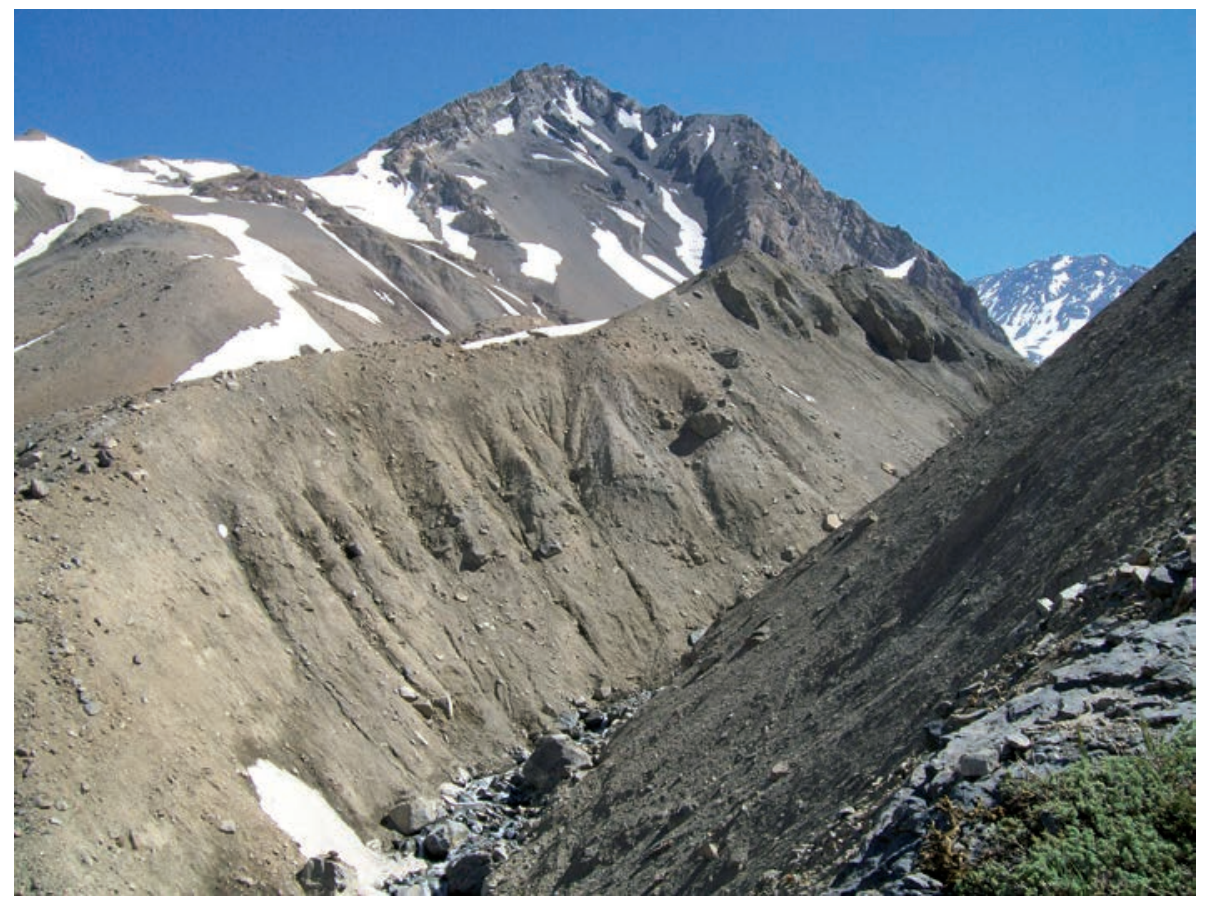

Fig. 13. Garganta abierta por el torrente proglacial en el penúltimo arco morrénico. El torrente, con bajo caudal, nace de filtraciones en la última morrena, atraviesa por un cauce poco encajado y algo ramificado el plano fluvioglacial y accede a este cauce fuertemente incidido, de flancos inestables y fondo caótico.

Fig. 13. Open gorge formed by the proglacial torrent in the penultimate morainal arc. The low runoff of the torrent is nourished by filtrations in the last moraine. From this moraine, the torrent drains a fluvioglacial plain and, forthwith, it crosses the gorge with instable slopes and a chaotic thalweg. 


\section{Mecanismos de alimentación}

Respecto de las actuales fuentes de alimentación, en el área del circo ellas se resumen en avalanchas de nieve que caen sobre él junto con algunos bloques de hielo que se desprenden de los glaciares colgantes de pocas dimensiones ubicado en la pared del circo. Sobre la superficie de toda la extensión de la lengua cubierta recibe precipitaciones sólidas, las que tanto según las rutas de nieve como por lo observado en las campañas de terreno lo cubren totalmente en invierno con 1 a 2 metros de espesor, y ocasionales tormentas de verano que depositan un manto nival discontinuo de algunos decímetros de grosor sobre su superficie y laderas adyacentes.

El agua de fusión de este manto de nieve percola a través del manto detrítico y deriva, según sean las temperaturas del momento, en agua recongelada que alimenta el glaciar o en flujos hídricos propios de la capa activa que aceleran el derretimiento y la movilización del manto detrítico, especialmente en los sectores de mayor pendiente. En los quiebres de pendiente de la superficie, así como en los sectores con presencia de escarpes con hielo expuesto, estos flujos ensucian dicha superficie, y producen movimientos en masa del tipo flujo de detritos así como desplome de bloques.

\section{Consunción y calentamiento global}

Aparte de los signos de inmovilidad o nulo desplazamiento, el fenómeno de la consunción se expresa fundamentalmente en lo caótico de la morfología superficial del hielo, hecho replicado por la cubierta morrénica, lo que es un signo morfológico claro de la fuerte ablación superficial derivada de un espesor de cubierta insuficiente en términos de aislamiento térmico. En este sentido, en el plano de contacto se genera un sistema de escurrimiento intra-detrítico (trough flow) a expensas del hielo, en el cual se organizan corrientes hídricas que aparecen en los escarpes de los colapsos internos y nutren las acumulaciones lagunares de sus fondos. Según las temperaturas, dichos flujos hídricos se presentan líquidos o congelados (Fig. 14).

$\mathrm{Al}$ respecto, se encuentra en desarrollo un análisis de los registros térmicos de estaciones meteorológicas altoandinas para establecer tendencias y relaciones causales con la dinámica que están presentando estas expresiones de permafrost.

En general, se trata de una capa activa en que se suman las aguas de fusión superficial del hielo cubierto a las aguas de fusión nival infiltradas, últimas que en estos años recién pasados (2009 a 2012) se consideran de menor importancia dada la escasa precipitación sólida registrada por el fenómeno La Niña imperante, es decir, la capa activa en este caso existe fundamentalmente a expensas de la ablación del glaciar.

Respecto de la génesis de las depresiones de colapso, la fusión interna abre conductos a expensas de las grietas y crea una red de escurrimiento con efectos desequilibrantes sobre la estructura gélida. De ahí los derrumbes de masas de hielo que revelan y exponen las consecuencias morfológicas de este proceso.

En este sentido, se podría hablar de "calving interno". En teoría, otra causa de los colapsos de la masa gélido-detrítica correspondería a fenómenos de reducción casi total de la fuerza de empuje, cuya compresión ayuda a dar soporte estructural y, consecuentemente, a mantener la integridad. 


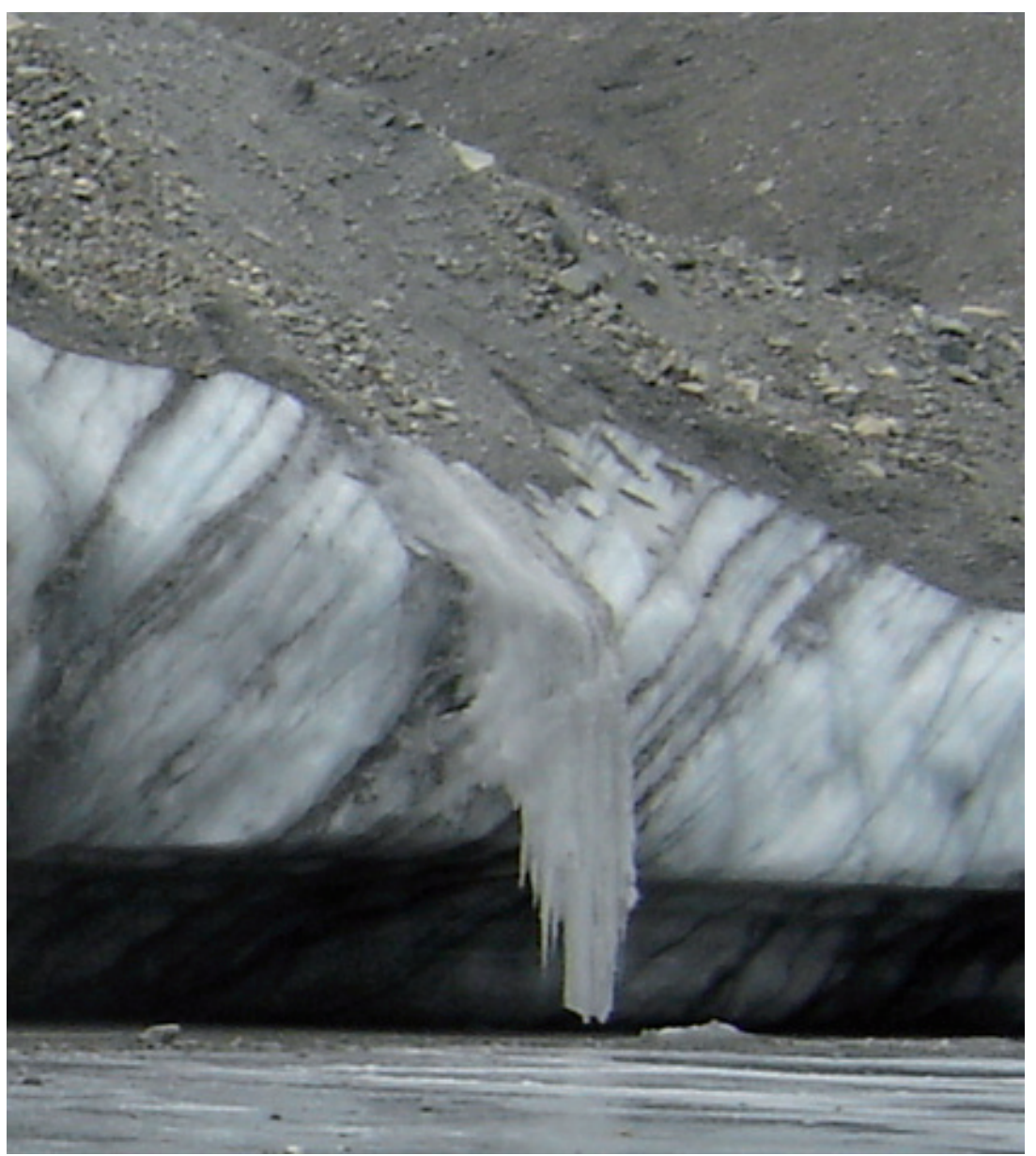

Fig. 14. Cascada congelada de agua de la capa activa.

Fig. 14. Frozen cascade formed by water of the active layer.

En cuanto a la cantidad y dimensiones de los colapsos que están afectando a este cuerpo detrítico-gélido, los distintos reconocimientos directos han permitido constatar aumentos en ambos sentidos. Estos hechos revelan que este glaciar cubierto está siendo fuertemente afectado por condiciones climáticas que están acelerando su derretimiento, situación que se ha visto agravada en los últimos 3 años producto del déficit de precipitaciones imperante dado el mantenimiento de la condición de La Niña desde el año 2009. En cuanto a las temperaturas, y ante la carencia de registros para los sectores altoandinos, el siguiente gráfico (Fig. 15) nos permite observar el tenor del ascenso de la isoterma de $0^{\circ} \mathrm{C}$ expresadas en anomalías estándar según datos de radiosondas de las estaciones de Quintero y Santo Domingo, lo cual nos muestra una tendencia clara de incremento entre el año $1971 \mathrm{y}$ el año 2006. 


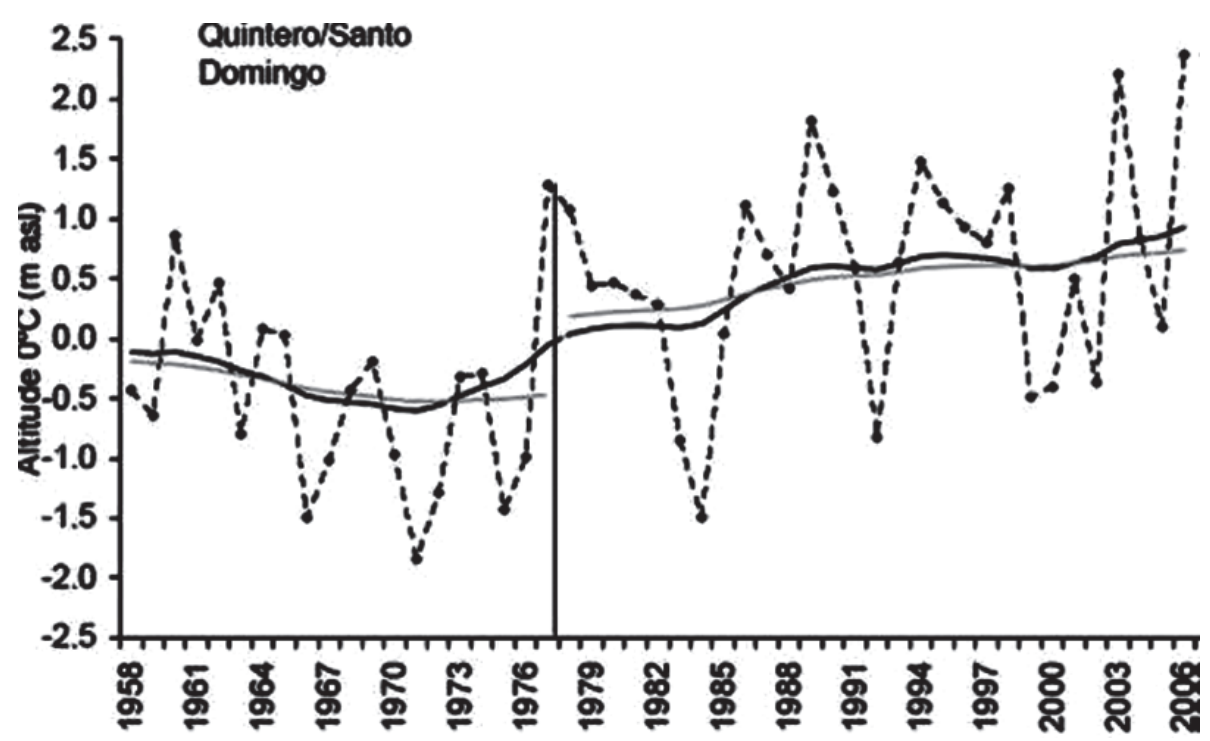

Fig. 15: La línea segmentada representa las alturas anuales medias de la isoterma de $0^{\circ} \mathrm{C}$ ( según PNUMA-Curso Glaciología 2010, Santiago, Chile).

Fig. 15. The dotted line shows the mean annual heights of the isotherm of $0^{\circ}$ (after PNUMACurso de Glaciología 2010, Santiago, Chile).

A la luz de los antecedentes, no cabe duda que glaciares cubiertos con mantos morrénicos poco espesos $(<$ de $3 \mathrm{~m})$ son altamente sensibles a los cambios de temperaturas entre el día y la noche así como estacionales, y con mayor razón si van acompañados de tendencias al incremento de mayor plazo, lo cual es parte de los fenómenos del actual escenario climático.

\section{CONCLUSIONES}

El glaciar Pirámide es un glaciar cubierto que, producto del poco espesor del manto morrénico superficial, presenta signos morfológicos evolutivos que reflejan su alta sensibilidad al incremento de las temperaturas derivadas del calentamiento global, lo que está demostrado por la tendenciade ascenso altitudinal mostrado por la isoterma de $0^{\circ} \mathrm{C}$.

Corroborando lo establecido por BRENNING et al. (2010), el espesor de varios decímetros del manto detrítico no actúa como aislante, sino como trasmisor del calor atmosférico, incrementador del caudal y efecto de la capa activa, entre otros, el de activador de procesos de alteración química.

La formación de ductos subglaciales de gran magnitud evidencia la gran cantidad de agua y fusión interna, consecuentemente el adelgazamiento general y, en especial, del techo de los ductos, lo cual esta provocando colapsos y derrumbes que han ido aumentando de tamaño en forma creciente, reflejando el efecto del incremento de las temperaturas ambientales. Los cuerpos lagunares que ocupan el fondo de las depresiones son otra evidencia de condiciones térmicas sobre $0^{\circ} \mathrm{C}$.

Dada su alta sensibilidad a los cambios en las condiciones climáticas, los glaciares cubiertos constituyen un sensor natural de las tendencias de las temperaturas $\mathrm{y}$, consecuentemente, del escenario de 
cambio o variabilidad climática que se esta manifestando en todo el mundo, y especialmente en los ambientes de montaña.

Considerando que, además de su sensibilidad térmica, constituyen un recurso hídrico no renovable a escala humana, se plantea la necesidad de intensificar el reconocimiento, monitoreo y estudio de estos cuerpos de permafrost discontinuo como una forma de mejorar las evaluaciones y gestión del recurso hídrico en el mediano y largo plazo, así como de seguir las variaciones de magnitud de los elementos del clima.

\section{REFERENCIAS}

BRENNING A. 2005. Climatic and geomorphological controls of rock glaciers in the Andes of Central Chile: Combining statistical modelling and field mapping. $\mathrm{PhD}$ dissertation, Humboldt-Universität zu Berlin.urn:nbn:de:kobv:11-10049648.

BRENNING, A., J. BODIN, D. TROMBOTTO, F. FERRANDO, G. AZOCAR, F. HERRERA \& J. HERNÁNDEZ, .2010. Glaciares rocosos en Chile semiárido: Plan de Monitoreo. Informe Técnico $\mathrm{N}^{\circ} 3$ y 4 . Ministerio de Obras Públicas-Dirección General de Aguas y Unidad de Proyectos. 71 pp.

CHEN, J. \& A. OHMURA, 1990. Estimation of Alpine glacier water resources and their change since the 1870s. In: Lang, H. \& A. Musy (Eds). Hydrology in Mountainous Regions, I - Hydrological Measurements; the Water Cycle. Proceedings of two Lausanne Symposia, August 1990. Oxfordshire:127-135.
FERRANDO, F. 2003. Aspectos Conceptuales y Genético-Evolutivos de los Glaciares Rocosos: Análisis de caso en los Andes Semiáridos de Chile. Revista Geográfica Terra Australis, 48: 43-74.

FERRANDO, F. 2002. Las Glaciaciones Cuaternarias en Chile: Visión general. Revista Geográfica de Chile Terra Australis, 47: 129-165.

MARANGUNIC, C. 1979. Inventario de glaciares: Hoya del Río Maipo. Technical Report. Dirección General de Aguas: Santiago, Chile.

MARANGUNIC, C. 2010. El movimiento de los glaciares y las estructuras resultantes. Apuntes Curso de Glaciología, Programa de Naciones Unidas para el Medio Ambiente, Santiago, inédito.

MEIER, M.F. \& D.B. BAHR, 1996. Counting glaciers: use of scaling methods to estimate the number and size distribution of the glaciers of the world. In: S.C. Colbeck (ed.), Glaciers, Ice Sheets and Volcanoes: A Tribute to Mark F. Meier. US Army CRREL, Hanover: 89-94. 